\title{
Telocytes in the urinary system
}

\author{
Yonghua Zheng ${ }^{1 \dagger}$, Tongyu Zhu ${ }^{3,4^{*}+}$, Miao Lin ${ }^{3}$, Duojiao $\mathrm{Wu}^{2,3}$ and Xiangdong Wang ${ }^{1,2}$
}

\begin{abstract}
Background: Telocytes, a new type of interstitial cells, have been identified in many organs in mammals. The present studies aimed at investigating the ultrastructure, distribution and interactions of telocytes with surrounding cells in the urinary system of rats, to confirm the existence of telocytes in kidneys, ureter and urinary bladder.

Methods: Samples of kidney, ureter, or urinary bladder were harvested for the ultrastructure by the electron microscope. The primary culture of telocytes was performed to investigate the dynamic alterations.

Results: Telocytes mainly located in the sub-capsular space of kidney, or between smooth muscle bundles and in the lamina propria of ureter and urinary bladder. Telocytes established numerous contacts with macrophages in the sub-capsular space of kidney, or with smooth muscle cells, nerve endings as well as blood capillaries in the ureter and urinary bladder. The complete morphology of telocytes with telopodes was observed clearly through the primary cell culture from the kidney tissues of rats.

Conclusions: Our data evidenced the existence of telocytes in the urinary system, which may contribute to the tissue reparation and regeneration.
\end{abstract}

Keywords: Telocytes, Kidney, Ureter, Urinary bladder

\section{Background}

There is increasing evidence of telocytes as a new type of interstitial cells recently, of which the most focused on the location and morphologic characteristics. Telocytes are characterized by specific ultrastructural features of telopodes thin fibrillar-like thin segments (podomeres) and dilated, beads-like thick regions (podoms) [1-3]. Telopodes contain a large number of mitochondria, endoplasmic reticulum and caveolae, and could secret exsomes. Telocytes per se or with others are connected by telpodes and the form of networks. Cismasiu VB et al. [4] found that miR-193 was highly expressed in telocytes rather than other stromal cells and suggested that telocytes could be specialized and characterized by the expression of miR-193, if the morphologies could be clarified. Telocytes were also identified in stem cell niches and connected with precursor stem cells in the heart, lung, skeletal muscle or skin

\footnotetext{
* Correspondence: tyzhu@fudan.edu.cn

${ }^{\dagger}$ Equal contributors

${ }^{3}$ Department of Urology Surgery, Fudan University, Zhongshan Hospital, No.180, Fenglin Road, Shanghai 200032, China

${ }^{4}$ Key Lab of Shanghai Organ Transplantation, Fudan University Zhongshan Hospital, No.180, Fenglin Road, Shanghai 200032, China

Full list of author information is available at the end of the article
}

[5-9]. It was indicated that telocytes might be associated with the regeneration and reparation of injured tissues and organs, through the signal transduction of telopodes and secretion of exsomes.

Telocytes were detected in a number of tissues/organs in mammals, e.g. heart [10-16], blood vessels [17], placenta [18], exocrine pancreas [19], intestine [20-22], trachea $[23,24]$, lungs $[7,23]$, pleura [25], skeletal muscle $[8,26]$, uterus and fallopian tube $[27,28]$, urinary tract [29], skin [9,30], endometrium [31], parotid glands [32], or meninges and choroid plexus [33]. There is still a lack of telocytes in the kidney and urinary bladder, even though telocytes were seen in the upper lamina propria of the human urinary tract [29]. The present study aimed to investigate the existence, characteristics, and distribution of telocytes in the kidney and urinary bladder and observe dynamic alterations of isolated and cultured telocytes from the kidney.

\section{Methods \\ Animals}

Three Sprague-Dawley rats were obtained and maintained from the animal research center of Fudan University, Shanghai, China. Rats, male, 8-week-old, weighing 200-250 g, were housed in a local facility for laboratory animal care and held, fed ad libitum, according to the

\section{Biomed Central}


local ethical guidelines. The study was approved by the Ethic Committee for Animal Care and Use, Fudan University, and performed according to accepted international standards.

\section{Transmission electron microscopy}

For ultrastructural analysis, tissue samples of kidney, ureter and urinary bladder were cut into small pieces about $1 \mathrm{~mm}^{3}$ within $1 \mathrm{~min}$ after being excised from rat body and immediately immersed in a solution of $4 \%$ glutaraldehyde $\left(\mathrm{pH} \quad 7.3,4^{\circ} \mathrm{C}\right)$. Fixed samples were washed in phosphate buffer, and were post-fixed in $1 \%$ osmium tetroxide (Polysciences Inc. Warrington, USA) for $1 \mathrm{hr}$. Samples were then rinsed extensively in $0.1 \mathrm{M}$ cacodylate buffer. Following several rinses in $0.1 \mathrm{M}$ cacodylate buffer, samples were dehydrated in a graded series of ethanol and were embedded in Epon 812 resin (Ted Pella Inc. California, USA). The embedded samples were dried by heat with serial temperatures $\left(37^{\circ} \mathrm{C}\right.$ for overnight, $45^{\circ} \mathrm{C}$ for $12 \mathrm{hrs}$ and $60^{\circ} \mathrm{C}$ for $48 \mathrm{hrs}$ ). Then sections of $50 \mathrm{~nm}$ were cut with a Leica Ultracut UCT ultramicrotome (Leica Microsystems Inc, LKB-II, Germany), stained with $3 \%$ solution of uranyl acetate and lead citrate, and mounted on formvar coated 50 mesh grids. Digital pictures $(2048 \times 2048$ pixels, $4 \mathrm{MB}$, and uncompressed grayscale Tiff files) were obtained using a high resolution digital camera MegaViewIII $\left(\mathrm{SIS}^{\circledR}\right)$ connected to the TEM, and observed at an acceleration voltage of $80 \mathrm{kV}$, in JEOL JEM-1230 (Japan) electron microscope.

\section{Isolation and primary cell culture of renal telocytes}

Rats were euthanized with pentobarbital sodium (1\%, $0.4 \mathrm{ml} / 100 \mathrm{~g}$ ) by peritoneal injection. The kidneys were cut and harvested under sterile conditions and collected into sterile tubes containing Dulbecco's Modified Eagle's Medium (DMEM, Gibco, New York, USA), supplemented with $100 \mathrm{UI} / \mathrm{ml}$ penicillin and $0.1 \mathrm{mg} / \mathrm{ml}$ streptomycin (Sigma Chemical, St. Louis, MO, USA), and the samples were brought to the cell culture room immediately. Under the sterile conditions, the kidney samples were rinsed with sterile DMEM and minced into fragments about $1 \mathrm{~mm}^{3}$, which were then incubated at $37^{\circ} \mathrm{C}$ for $4 \mathrm{hrs}$ on an orbital shaker, with $10 \mathrm{mg} / \mathrm{ml}$ type II collagenase (Sigma, St. Louis, MO, USA) in PBS without $\mathrm{Ca}^{2+}$ and $\mathrm{Mg}^{2+}$. Dispersed cells were separated from non-digested tissue by the filtration through a $40 \mu \mathrm{m}$ diameter cell strainer (BD Falcon, Franklin, New Jersey, USA), collected by centrifugation at $2000 \mathrm{rmp}, 5 \mathrm{~min}$, and were resuspended in DMEM, supplemented with $10 \%$ fetal calf serum (Gibco, New York, USA), $100 \mathrm{UI} / \mathrm{ml}$ penicillin and $0.1 \mathrm{mg} / \mathrm{ml}$ streptomycin. Cell density was counted in a haemocytometer and viability was assessed using the Trypan blue dye exclusion test. Cells were distributed in $25 \mathrm{~cm}^{2}$ plastic culture flasks, at a density of $1 \times 10^{5} \mathrm{cells} / \mathrm{cm}^{2}$, and maintained in a humidified incubator at $37^{\circ} \mathrm{C}$ with $5 \% \mathrm{CO}_{2}$ until becoming semi-confluent (usually 4 days after plating). Culture medium was changed every $48 \mathrm{hrs}$. Cultured cells were examined by phase contrast microscope, under an inverted Olympus phase contrast microscope $(1 \times 51)$, and the typical telocytes were photographed.

\section{Results}

Transmission electron microscopy

In kidney, telocytes with long telopode could be seen clearly in sub-capsular space, and they connected with

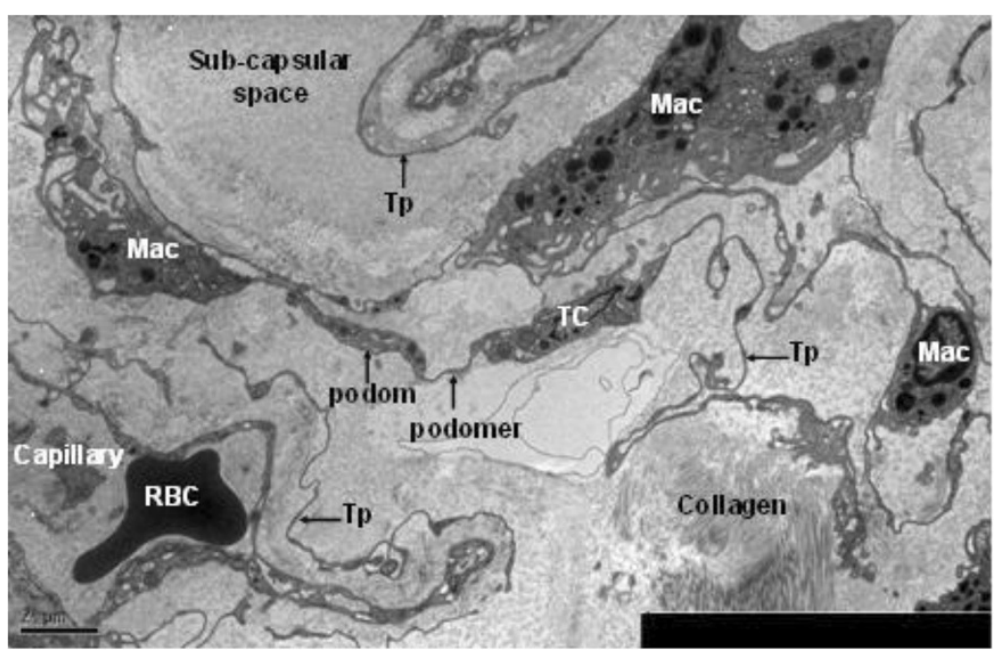

Figure 1 TEM of rat kidney. A Telocyte with its long telopode is visible under sub-capsular space of kidney, and it is near the capillary. Noting the striking labyrinthine network formed by telopode. Telopode is very long with alternation of podom and podomer. Telocyte connects with macrophages by telopode. (TC: telocyte; Tp: telopode; Mac: macrophage; RBC: red blood cell). Magnification is 5000x, and the scale bar is $2 \mu$ m. 


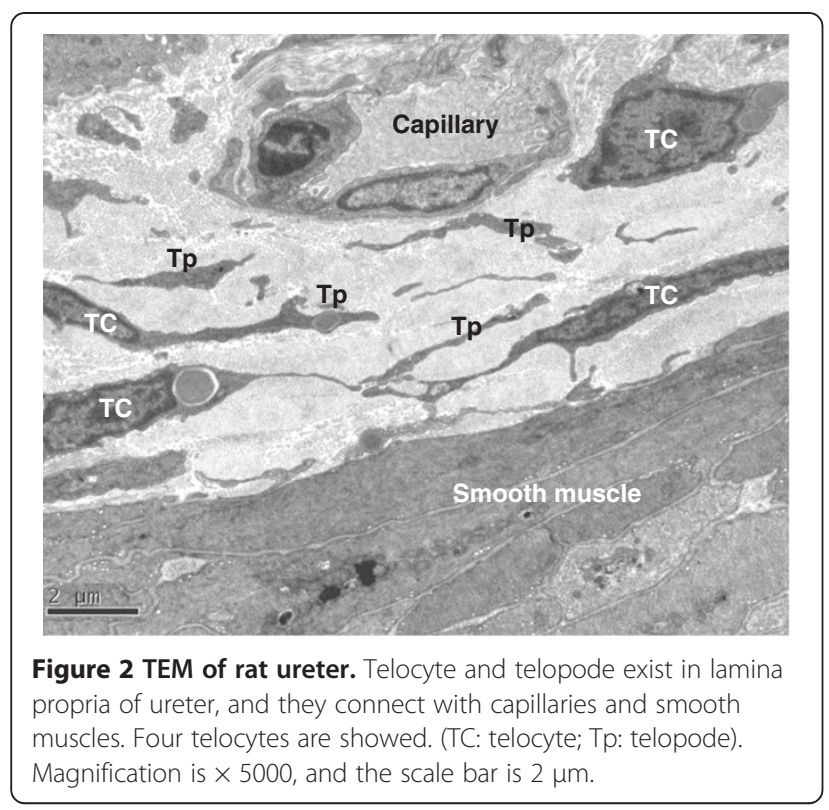

macrophages through telopode. Telopodes were detected as discontinuous segments with alternation of podom and podomer due to the three dimensional extension of telopode. Telocytes connected with telopodes and existed near the blood vessels, and there were network structures or labyrinthine structure, between telopodes (Figure 1).

In ureter and urinary bladder, telocytes mainly exist in between smooth muscle bundles, where in the lamina propria, and their telopodes made a network which appeared like labyrinthine structure and were also detected as discontinuous segments with alternation of podom and podomer. The nucleus of telocytes appeared in irregular shapes and contained clusters of heterochromatin attached to the nuclear envelope. Telocytes are connected with smooth muscles, capillaries and never endings (Figure 2, Figure 3, Figure 5) by their long telopodes. Telocytes could connect with each other closely through their telopodes, as shows in Figure 4.

\section{Primary cell culture of telocytes}

In our study, telocytes were cultured and identified at the third day before reaching confluence. Telocytes with long telopodes and uneven podoms and podomers were observed from the third and fourth days on (Figure 6). The length seemed to be related with the duration of culture in the short term of cell growth, although the mechanism and long-term situation remain unclear. We found that telopodes could connect with each other frequently by either side-to-side of telopodes (Figure 6A) or end-to-end of telopodes (Figure 6B) and occasionally by end-to-side. This implies that the telopodes might deliver the signal either by the pass-by during cellular functioning or special and unique communication between telocytes. The shape of telocytes changed at different time schedules and telopodes changed from wide to thin. Telopodes extended and moved, leading to

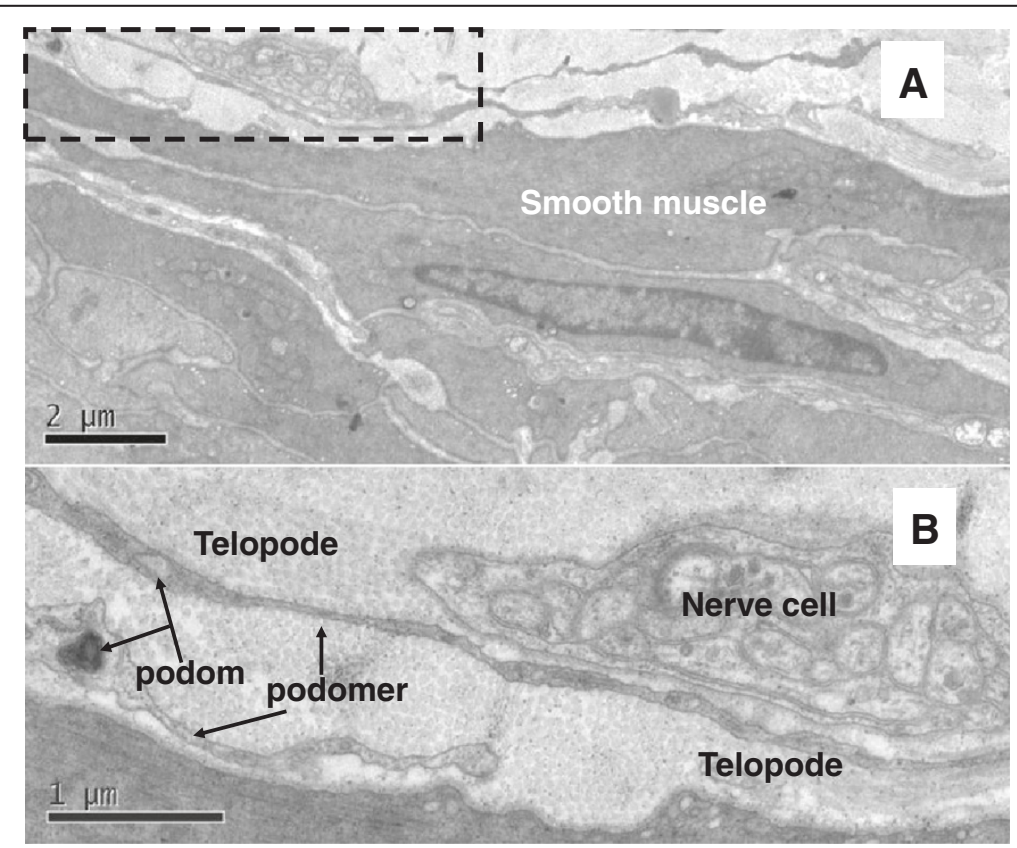

Figure 3 TEM of rat ureter. A shows telopode exist in lamina propria of ureter, and it connects with never ending. Podom and podomer are showed clearly. Magnification is $\times 5000$, and the scale bar is $2 \mu \mathrm{m}$. B is the enlargement of black dotted frame in A. Magnification is $\times 15000$, and the scale bar is $1 \mu \mathrm{m}$. 


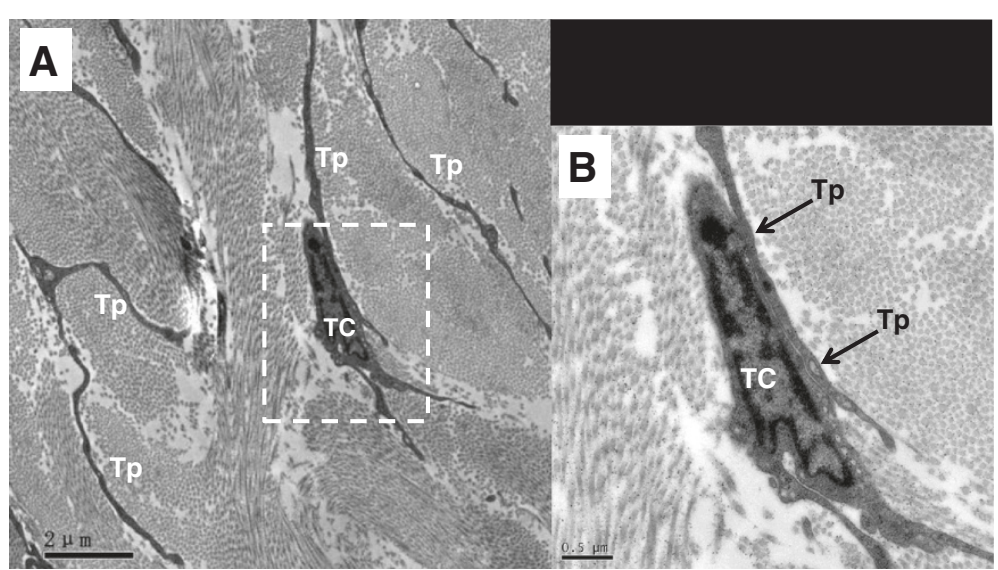

Figure 4 TEM of rat ureter. A shows typical telopodes (Tp) and telocytes (TC) in the ureter, and telocytes connect with telopodes from other telocytes. $\mathbf{B}$ is the enlargement of white dotted frame in A, and the details about the connection between telcoytes (TC) and telopode (Tp, black arrow) are showed clearly. Magnification of A is $5000 \times$, and the scale bar is $2 \mu \mathrm{m}$. Magnification of B is $20000 \times$, and the scale bar is $0.5 \mu \mathrm{m}$.

alternation of thin segments (podomers) and dilations (podoms) (Figure 6C and D).

\section{Discussion}

The special cells we identified in the urinary system of rats were in line with the diagnostic criteria of telocytes, which was defined by Popescu et al. in 2010[1]. As it was showed in the results, telocytes were identified in the interstitial spaces of urinary system in rats, and this added new evidence for the existence of telcoytes in the mammals. Based on our own study, about

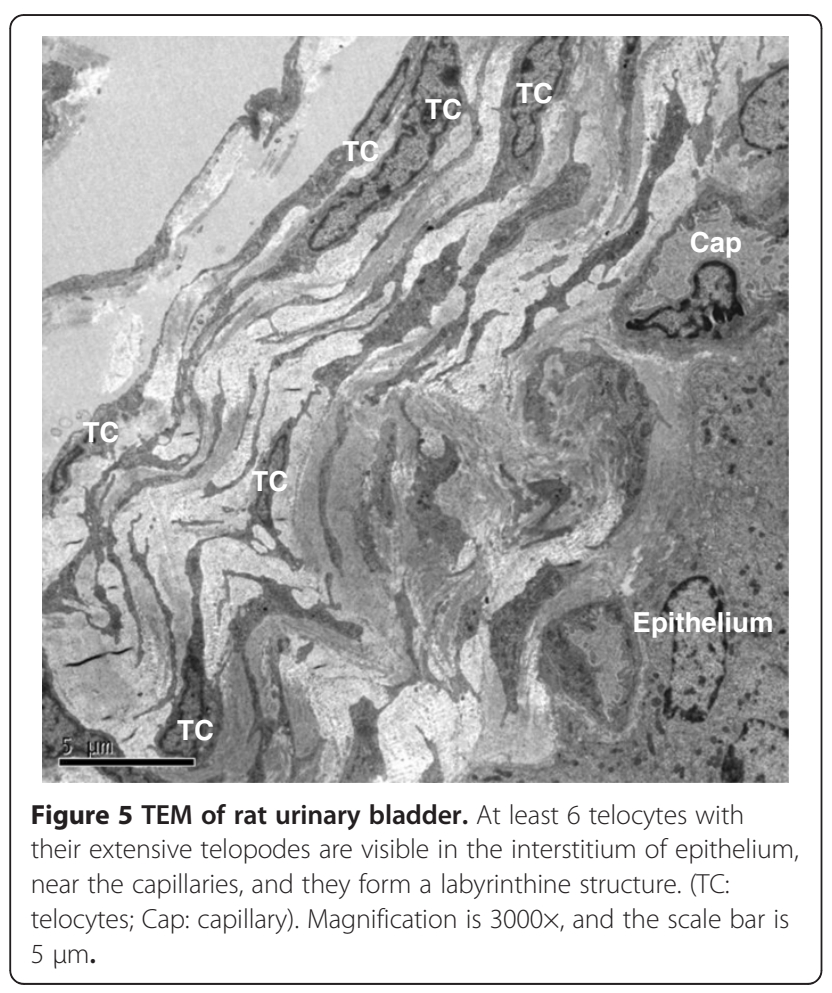

2-3 telopodes were observed on a single section, dependent upon the site and angle of section, since it was hardly to see 3 dimensional convolutions of telopode at the full length in a section. The lengths of telopodes were tens to hundreds of micrometers, as measured on EM images [1], while it was detected during cell cultures in the present study. The length seemed to be related with the duration of culture in the short term of cell growth, although the mechanism and long-term situation remain unclear. We found that telopodes could connect with each other frequently by either end-to-end or side-to-side and occasionally by end-to-side. This implies that telopodes might deliver the signal either by the pass during cellular functioning or by special and unique communication between telocytes, as described by Suciu L et al. [33]. Because the morphology and structure of the cells are always associated with their functions, there must be many other important functions for telocytes.

According to the published results, some potential roles of telocytes could be summarized. Popescu et al. [1] suggested that telocytes were involved in intercellular signaling, for their three dimensional network of telopodes and their strategic position with other cells, blood capillary and nerve ending. Telcoytes also play roles in vascular system, nervous system, immune system, interstitium and stem cells/progenitors [6]. Laura Suciu et al. [18] suggested that telcoytes might be involved in the angiogenesis, since they found telocytes expressed CD34 and VEGF. Manole CG et al. [34] found that telocytes involved in neo-angiogenesis in the experimental acute myocardial infarction. Telocytes might be involved in tissue regeneration and reparation $[9,26]$.

The function of telocytes in kidney might be involved in the reparation of injured tissues and immune reflections during diseases such as acute kidney injury, renal 

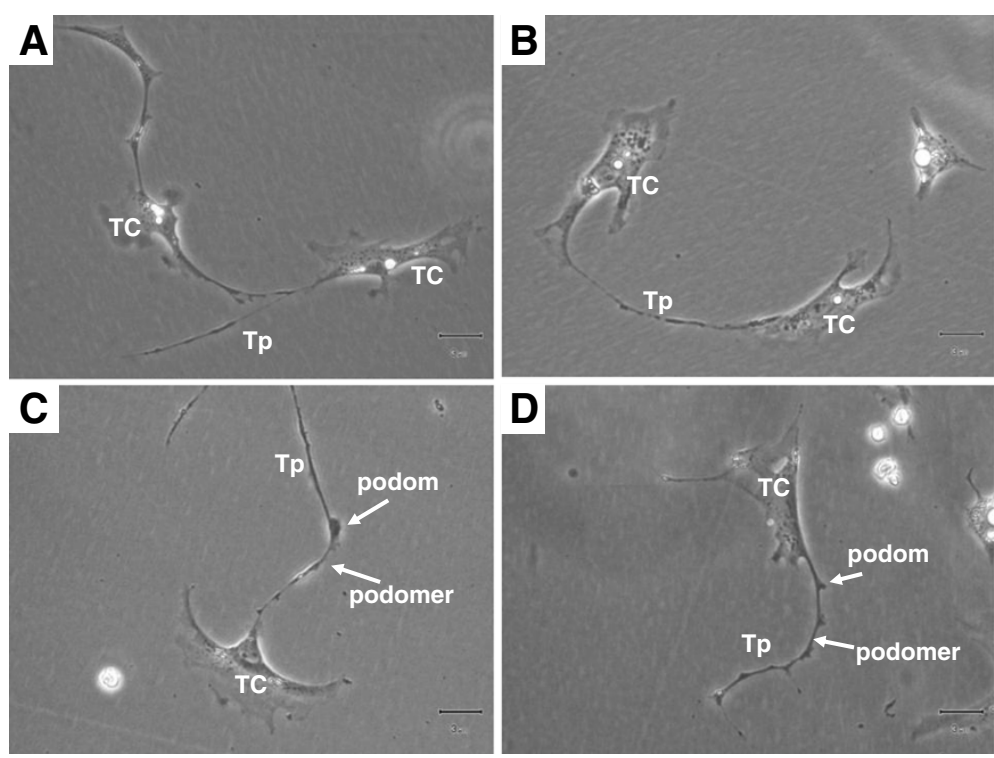

Figure 6 Telocytes from rat sub-capsular space of kidney. Primary culture, 5 days. There are two telocytes with typical Tp in A/B, and they connect together. Single telocyte with typical telopode (alternation with podom and podomer) could be seen in C/D clearly. (TC: telocytes; Tp: telopode). Magnification is $200 x$, and the scale bar is $3 \mu \mathrm{m}$.

failure and renal fibrosis. It is supported by our findings that telocytes and telopodes were located in close vicinity of blood capillaries and connected with macrophages in the sub-capsular space of kidney. The existence of telopodes and the 3 dimentional network implies that telocytes may play an important role in the intercellular communication and regulation [3]. The function of telocytes in ureter and urinary bladder might be involved in the reparation of injured tissues during diseases, like in the skeletal muscles [26]. It is supported by our findings that telocytes and telopodes were located in close vicinity of blood capillaries, nerve endings and smooth muscles. However, there is a great need to explore telocyte-specific biomarker to clarify the cell in the functional aspect and in an easier way, network biomarkers to understand more about the interaction between proteins, genes, and signal pathways, and dynamic network works to define and predict time-dependent telocyte function and morphological features [35-38]. It will be more challenging to translate those experimental knowledge and evidences into the understanding of diseases and application of clinical diagnoses and therapies in the aspects of clinical and translational medicine [34,39-41].

In conclusion, the present study provided ultrastructural evidence for the existence of telocytes in kidney, ureter and urinary bladder. Telopodes connect each other by end-to-end or side-to-side both in the tissue and cell culture. There are still further needs to explore potential bio-functions of telocytes in certain pathological conditions in urinary system and mechanism of interaction between telocytes and other cells.

\section{Competing interests}

The authors declare that they have no competing interests.

\section{Authors' contributions}

YHZ performed studies, result calculation, images processing, and the writing of manuscript. TYZ participated in the design of the study and images processing. ML performed the study. DJW participated in the design of the study. XDW participated in the design, result calculation and analysis, and helped to draft the manuscript. All authors read and approve the final manuscript.

\section{Acknowledgements}

The work was supported by Shanghai Leading Academic Discipline Project (Project Number: B115), Fudan University (Distinguished Professor Grant), and Shanghai Science \& Technology Committee (11410708600, 12JC1402200, 12431900207), and National Nature \& Science Foundation (H0108). The authors would like to thank Department of Electronic Microscopy, Shanghai Medical College, Fudan Universtiy, for the technical assistance in TEM, and Miaomiao Zhang, Dongli Song, Mengjia Qian and Lingyan Wang for their kind helps.

\section{Author details}

'Department of Pulmonary Medicine, Fudan University, Zhongshan Hospital, No.180, Fenglin Road, Shanghai 200032, China. ${ }^{2}$ Biomedical Research Center, Fudan University, Zhongshan Hospital, No.180, Fenglin Road, Shanghai 200032, China. ${ }^{3}$ Department of Urology Surgery, Fudan University, Zhongshan Hospital, No.180, Fenglin Road, Shanghai 200032, China. ${ }^{4}$ Key Lab of Shanghai Organ Transplantation, Fudan University Zhongshan Hospital, No.180, Fenglin Road, Shanghai 200032, China.

Received: 13 May 2012 Accepted: 6 September 2012

Published: 10 September 2012

\section{References}

1. Popescu LM, Faussone-Pellegrini MS: TELOCYES-a case of serendipity: the winding way from Interstitial Cells of Cajal (ICC), via Interstitial Cajal-Like Cells (ICLC) to Telocytes. J Cell Mol Med 2010, 4:729-740.

2. Zheng $Y$, Bai $C$, Wang $X$ : Potential significance of telocytes in the pathogenesis of lung diseases. Expert Rev Respir Med 2012, 6:45-49.

3. Zheng $Y$, Bai $C$, Wang $X$ : Telocyte morphologies and potential roles in diseases. J Cell Physiol 2012, 227:2311-2317. 
4. Cismasiu VB, Radu E, Popescu LM: miR-193 expression differentiates telocytes from other stromal cells. J Cell Mol Med 2011, 15:1071-1074.

5. Gherghiceanu M, Popescu LM: Cardiomyocyte precursors and telocytes in epicardial stem cell niche: electron microscope images. $J$ Cell Mol Med 2010, 14:871-877.

6. Gherghiceanu M, Popescu LM: Cardiac telocytes-their junctions and functional implications. Cell Tissue Res 2012, 348:265-279.

7. Popescu LM, Gherghiceanu M, Suciu LC, Manole CG, Hinescu ME: Telocytes and putative stem cells in the lungs: electron microscopy, electron tomography and laser scanning microscopy. Cell Tissue Res 2011, 345:391-403.

8. Bojin FM, Gavriliuc Ol, Cristea Ml, et al: Telocytes within human skeletal muscle stem cell niche. J Cell Mol Med 2011, 15:2269-2272.

9. Ceafalan L, Gherghiceanu M, Popescu LM, Simionescu O: Telocytes in human skin; are they involved in skin regeneration. J Cell Mol Med 2012, 16(7):1405-20

10. Rusu MC, Pop F, Hostiuc S, Curca GC, Jianu AM, Paduraru D: Telocytes form networks in normal cardiac tissues. Histol Histopathol 2012, 27:807-816.

11. Gherghiceanu M, Popescu LM: Heterocellular communication in the heart: electron tomography of telocyte-myocyte junctions. J Cell Mol Med 2011, 15:1005-1011.

12. Kostin S, Popescu LM: A distinct type of cell in myocardium: interstitial Cajal-like cells (ICLCs). J Cell Mol Med 2009, 13:295-308.

13. Kostin S: Myocardial telocytes: a specific new cellular entity. J Cell Mol Med 2010, 14:1917-1921.

14. Zhou J, Zhang Y, Wen X, Cao J, Li D, Lin Q, Wang H, Liu Z, Duan C, Wu K, Wang $\mathrm{C}$ : Telocytes accompanying cardiomyocyte in primary culture: two- and three-dimensional culture environment. J Cell Mol Med 2010, 14:641-2645.

15. Gherghiceanu M, Popescu LM: Human epicardium: ultrastructural ancestry of mesothelium and mesenchymal cells. J Cell Mol Med 2009, 13:2949-2951.

16. Popescu LM, Manole CG, Gherghiceanu M, Ardelean A, Nicolescu MI, Hinescu ME, Kostin S: Telocytes in human epicardium. J Cell Mol Med 2010, 14:2085-2093.

17. Cantarero I, Luesma MJ, Junquera C: The primary cilium of telocytes in the vasculature: electron microscope imaging. J Cell Mol Med 2011, 15:2594-2600.

18. Suciu L, Popescu LM, Gherghiceanu M, Regalia T, Nicolescu MI, Hinescu ME, Faussone-Pellegrini MS: Telocytes in human term placenta: morphology and phenotype. Cells Tissues Organs 2010, 192:325-339.

19. Nicolescu MI, Popescu LM: Telocytes in the interstitium of human exocrine pancreas: ultrastructural evidence. Pancreas 2012, 41:949-56.

20. Cantarero Carmona I, Luesma Bartolomé MJ, Junquera Escribano C: Identificati -on of telocytes in the lamina propria of rat duodenum: transmission electron microscopy. J Cell Mol Med 2011, 15:26-30.

21. Radenkovic G: Two patterns of development of interstitial cells of Cajal in the human duodenum. J Cell Mol Med 2011, 16:185-192

22. Cretoiu D, Cretoiu SM, Simionescu AA, Popescu LM: Telocytes, a distinct type of cell among the stromal cells present in the lamina propria of jejunum. Histol Histopathol 2012, 27:1067-1078.

23. Zheng Y, Manole CG, Bai C, Wang XD: Telocyes in trachea and lungs. J Cell Mol Med 2011, 15:2262-2268.

24. Rusu MC, Jianu AM, Mirancea N, Didilescu AC, Manoiu VS, Paduraru D: Tracheal telocytes. J Cell Mol Med 2012, 16:401-405.

25. Hinescu ME, Gherghiceanu M, Suciu L, Popescu LM: Telocytes in pleura: two- and three-dimensional imaging by transmission electron microscopy. Cell Tissue Res 2011, 343:389-397.

26. Popescu LM, Manole E, Serboiu CS, Manole CG, Suciu LC, Gherghiceanu M, Popescu BO: Identification of telocytes in skeletal muscle interstitium: implication for muscle regeneration. J Cell Mol Med 2011, 15:1379-1392.

27. Popescu LM, Ciontea SM, Cretoiu D: Interstitial Cajal-like cells in human uterus and fallopian tube. Ann N Y Acad Sci 2007, 1101:139-165.

28. Cretoiu SM, Cretoiu D, Suciu L, Popescu LM: Interstitial Cajal-like cells of human Fallopian tube express estrogen and progesterone receptors. J Mol Histol 2009, 40:387-394

29. Gevaert T, De Vos R, Van Der Aa F, et al: Identification of telocytes in the upper lamina propria of the human urinary tract. J Cell Mol Med 2011, 16:2085-93.

30. Rusu MC, Mirancea N, Manoiu VS, Valcu M, Nicolescu MI, Paduraru D: Skin telocytes. Ann Anat 2011, 194:359-67.

31. Hatta K, Huang ML, Weisel RD, Li RK: Culture of rat endometrial telocytes. J Cell Mol Med 2012, 16:1392-6.
32. Nicolescu MI, Bucur A, Dinca O, Rusu MC, Popescu LM: Telocytes in parotid glands. Anat Rec (Hoboken) 2012, 295:378-385.

33. Popescu BO, Gherghiceanu M, Kostin S, Ceafalan L, Popescu LM: Telocytes in meninges and choroid plexus. Neurosci Lett 2012, 516:265-269.

34. Manole CG, Cismasiu V, Gherghiceanu M, Popescu LM: Experimental acute myocardial infarction: telocytes involvement in neo-angiogenesis. J Cell Mol Med 2011, 15(11):2284-2296.

35. Chen $H$, Wang XD: Significance of bioinformatics in research of chronic obstructive pulmonary disease. J Clin Bioinforma 2011, 20:1-35.

36. Wang $X D$, Liotta $L$ : Clinical bioinformatics: a new emerging science. J Clin Bioinforma 2011, 1:1.

37. Wang XD: Role of clinical bioinformatics in the development of networkbased Biomarkers. J Clin Bioinforma. 2011, 1:28.

38. Wu DJ, Rice CM, Wang XD: Cancer bioinformatics: A new approach to systems clinical medicine. BMC Bioinformatics 2012, 13:71.

39. Fang $X$, Bai C, Wang XD: Bioinformatics insights into acute lung injury/ acute respiratory distress syndrome. Clin Trans/ Med 2012, 1:9.

40. Wang XD, Marincola FM: A decade plus of translation: what do we understand? Clin Trans/ Med 2012, 1:3

41. Wang XD: A new vision of clinical and translational medicine: definition, commentary, understanding. Clin Trans/ Med 2012, 1:5.

doi:10.1186/1479-5876-10-188

Cite this article as: Zheng et al:: Telocytes in the urinary system. Journal of Translational Medicine 2012 10:188.

\section{Submit your next manuscript to BioMed Central and take full advantage of:}

- Convenient online submission

- Thorough peer review

- No space constraints or color figure charges

- Immediate publication on acceptance

- Inclusion in PubMed, CAS, Scopus and Google Scholar

- Research which is freely available for redistribution

Submit your manuscript at www.biomedcentral.com/submit
C) Biomed Central 